\title{
Kunst für die Stiftung «Welt ohne Minen»
}

David Künzler

Korrespondenz:

Dr. med. David Künzler Jakob Zürrerstrasse 35

CH-8915 Hausen am Albis
Mitglieder der Vereinigung der malenden Ärztinnen und Ärzte haben in der Galerie zur Hammermühle in Ibach schon zum dritten Mal Bilder zum Verkauf ausgestellt. Und wie immer geht der Gewinn an die Stiftung «Welt ohne Minen». Sie hat es sich zur Aufgabe gemacht, so viele Minen wie möglich zu entschärfen und dadurch Tod und Leid zu verringern. Sie hilft auch, dass den Verletzten im Rahmen des Möglichen geholfen wird, sich z. B. durch Prothesen wieder bewegen zu können, dass sie arbeiten, oft sogar Sport treiben, lustig sein - eben leben können.

In diesem Zusammenhang thematisierte David Künzler, Präsident der Vereinigung malender Ärztinnen und Ärzte, in seiner Ansprache den Aspekt, dass anders als im wirklichen Leben - in der Kunst auch etwas nicht Vollständiges, ein Torso etwa, als schön gelte. So verkörpere nicht nur Michelangelos «David»

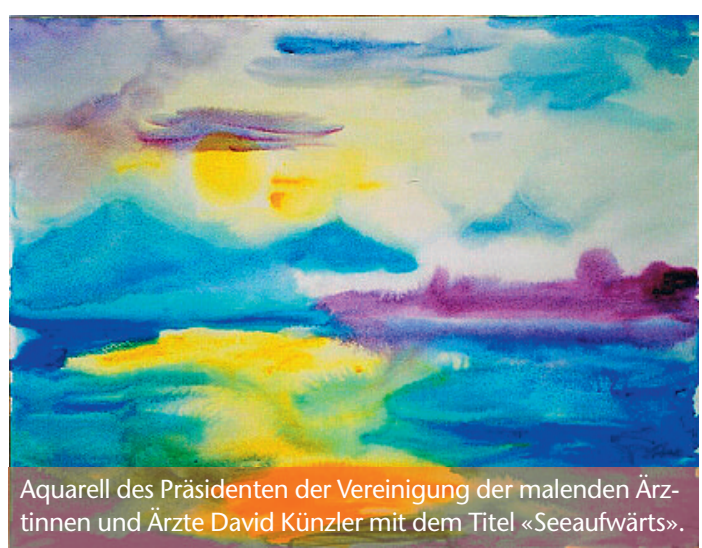

das Schöne und Ganze, wonach die Kunst immer strebe. Am Beispiel eines Bildes von Georg Baselitz, das einen zerstückelten, zum Teil verdreht zusammengesetzten Menschen darstellt, zeigte er, dass auch dieses Werk in seiner Art vollständig und von eigener Schönheit sei.

Von der Kunst fiel der Blick dann auf ein Kind mit einem fehlenden Unterschenkel, abgetrennt durch eine Mine. Minen sind sicher die hinterhältigste und unmenschlichste Art, Gegner und leider auch viel zu viele unbeteiligte, unschuldige Menschen zu zerstören, zu zerteilen und letztlich in den Tod zu reissen. Trotz eines Verbots des Einsatzes von Minen durch die UNO halten sich gerade die Mächtigsten, wie etwa die USA und Russland, nicht an das Verbot und geben so ein trauriges Beispiel. Viele Widerstandsgruppen tun dasselbe, mit dem Effekt, dass die sie bekämpfenden Militärs das Gleiche tun - oder umgekehrt.

Dass in vielen Gebieten Millionen von noch scharfen Minen liegen, macht das Leben dort zu einer Art psychischer Folter, da man nie weiss, wann man auf

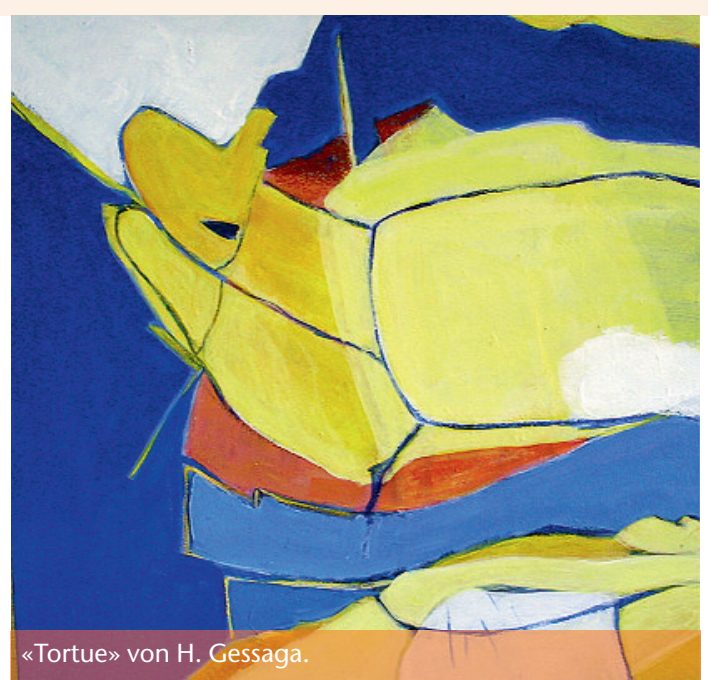

eine solche tritt. Und grausamerweise sind vor allem Kinder gefährdet. Zynisch an der Situation ist zudem, dass die sicher verbrecherisch zu nennenden Ausleger der Minen diese nicht mehr selbst entfernen müssen bzw. entschärfen wollen, sondern das infam anderen, menschlich Denkenden überlassen, die dies dann unter Lebensgefahr tun.

Mit dem Verkauf unserer Vollständigkeit zeigenden und schönen Werke und der Übergabe des Gewinns an die Stiftung «Welt ohne Minen» hoffen wir, Leid zu mindern und zu helfen, dass Zerstörtes bestmöglich wieder hergestellt werden kann. Die Welt könnte so eine Spur schöner werden.

Weitere Informationen:

Galerie: www.hanni-mirer.ch

Kunstausstellung: www.aerzte-kunst.ch Stiftung «Welt ohne Minen»: www.wom.ch

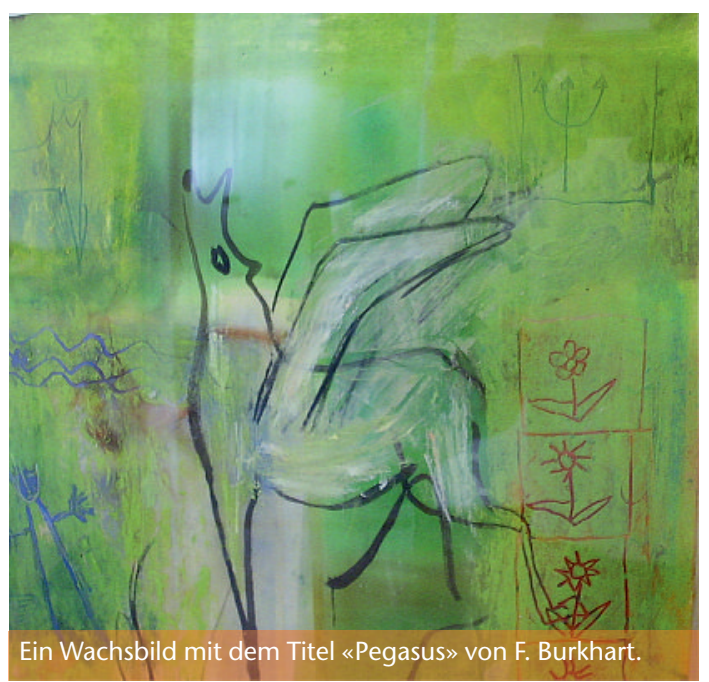

